\title{
Small Bowel Tumors: What the Surgeon Can Not Forget
}

\author{
Aline Vasconcelos de Carvalho ${ }^{1}$; Arnaldo Costa de Medeiros Junior ${ }^{\mathbf{1}}$; Bárbara \\ Monitchelly Fernandes Chaves ${ }^{1}$; Edlana Rebouças Veloso Guimarães ${ }^{1}$; Amália Cinthia \\ Meneses Rêgo ${ }^{2}$; Irami Araújo-Filho ${ }^{3}$; Aldo Cunha Medeiros ${ }^{4}$. \\ ${ }^{1}$ Graduating Medical University Potiguar - Laureate International Universities \\ ${ }^{2}$ Director of the School of Health University Potiguar - Laureate International Universities \\ ${ }^{3}$ Associate Professor of General Surgery at the University Potiguar - Laureate International \\ Universities \\ ${ }^{3}$ Full Professor of General Surgery at the Rio Grande do Norte Federal University \\ ${ }^{4}$ Full professor of General Surgery at the Rio Grande do Norte Federal University \\ irami.filho@uol.com.br/irami.filho@gmail.com
}

\begin{abstract}
The jejunum and ileum neoplasms, in addition to rare diseases, have some difficulty of suspicion due to an arsenal of nonspecific signs and symptoms, responsible for diagnostic delay main. Adenocarcinomas, carcinoid tumors, lymphomas and sarcomas are tumors of evil nature, while adenomas, leiomyomas, fibromas and lipomas make up the benign. The general principle of treatment of primary small intestine malignant blastomas is resection with free surgical margins, associated or not to locoregional lymphadenectomy, depending on the histological type and surgical staging of neoplasia.
\end{abstract}

Keywords: Intestinal Neoplasms; Neoplasms; small intestine; jejunum; ileum; malignant tumors.

\section{INTRODUCTION}

In all age groups, the tumors of the small intestine are rare, corresponding to about $1 \%$ to $6 \%$ of all Neoplasms of the gastrointestinal tract[1]. the low specificity of the clinical picture is the main factor of diagnostic difficulty.

\section{MATerial AND Methods}

This is a review of literature on the Neoplasms of the small intestine, using the above descriptors researched in the databases PubMed, Lilacs, Scopus, Scielo and Web of Science, using articles published between 1985 and 2015.

\section{Pathophysiology}

Several theories, based on the original microenvironment of the small intestine, have been proposed to explain this low rate [1]. The content that runs through the small intestine is more liquid and diluted to the present in the colon, causing less irritation to the mucous membrane, as well as the traffic of this first content is fast, leading to decreased exposure to carcinogens substances[2].The much lower bacterial load, particularly anaerobic bacteria in the small intestine can result in less conversion of bile acids in potential carcinogens by anaerobic organisms. The benzopyrene, carcinogen in foods, is converted to less toxic metabolites by hydroxylase-benzopyrene, present in high concentrations in the small intestine, in comparison to the stomach and colon. Finally, the protective action of the presence of lymphoid and $\operatorname{IgA}$, found in large quantities in the small intestine, constitute some of the premises of pathogenesis [2.3-5].

\section{EPIDEMiology}

The average age at diagnosis is 65 years old, with lymphomas and sarcomas in little younger population (60 to 62 years) compared to carcinoid and adenocarcinoma (67 to 68 years)[4.5]. There is a slight male predominance in a man: woman of 1.5 rate: 1.0 and a series of studies report higher incidence in blacks than in whites [4.5-7]. 


\section{RISK FACTORS}

Among the main risk factors, hereditary cancer syndromes (hereditary nonpolyposis colorectal cancer, involves familiar Adenomatosis, Peutz-Jeghers Syndrome), chronic inflammation (Crohn's disease and celiac), Neuroendocrine tumors, diets high in red meat, preservatives, smoked, in addition to smoking and obesity [3,8].

\section{Diagnosis}

The diagnosis, conducted through histopathologic mostly is difficult due to the rarity of these injuries, as well as the nonspecific and variable nature of the signs and symptoms present ${ }^{2}$, such as abdominal pain, intestinal occlusion episodes, digestive bleeding, weight loss and palpable mass, which are expressions that make up a variety of digestive disorders. Thus, the delay in diagnosis is common, which may result in the discovery of the disease at a late stage and a bad result of treatment[3-6,9].

The differential diagnosis is broad, given the nonspecific symptoms. The most common causes of stenosis and obstruction of the small intestine include adhesions, incarceration of hernia, intestinal inflammatory disease, endometriosis and complications of appendicitis or diverticulitis $[10,11]$.

\section{TyPES AND ChaRACTERISTICS}

Adenocarcinomas, lymphomas, and sarcomas carcinoids are tumors of evil nature, while adenomas, leiomyomas, fibromas and lipomas make up the benign [3].

The benign in nature are more common than malignant, and the epithelial origin are among the most frequently. The adenomatous polyps and vilosos can be sessile or layer. The latter are associated with bleeding and intestinal obstruction (intussusception), as well as a low malignancy potential and controversial. The small intestine, the duodenum, and the jejunum shelter, in order of frequency, the majority of these lesions [7].

Although they can be found throughout the different regions of the gut, certain subtypes have a predilection for specific regions. Adenocarcinoma is the most common malignancy affecting the duodenum, is the most common tumor carcinoid in ileum, while and sarcomas lymphomas may develop throughout the small intestine. In a series based on the 67.843 small bowel malignancy cases reported to the National Cancer Database between 1985 and 2005, the distribution of tumor type according to the location of the small intestine has been described[4,9-11].

Table1. Distribution of Primary Tumors of Small Intestine

\begin{tabular}{|l|l|l|l|l|}
\hline \multirow{2}{*}{ Location } & \multicolumn{3}{|c|}{ Primary Neoplasms of the small intestine (\%) } \\
\cline { 2 - 5 } & Carcinoid * & Adenoma & Lymphoma & Sarcoma * \\
\hline Duodenum & 12 & 56 & 18 & 16 \\
\hline Jejunum & 06 & 16 & 16 & 25 \\
\hline Ileum & 45 & 13 & 21 & 15 \\
\hline $\begin{array}{l}\text { Overlapping disease or of } \\
\text { unspecified location }\end{array}$ & 32 & 15 & 46 & 44 \\
\hline
\end{tabular}

* Percentages were rounded, so the total exceeds 100. From: KY, Bilimoria Bentrem DJ, Wayne JD, et al. Ann Surg 2009; 249:63.

The lineage of the epithelial benign Neoplasms not the small intestine include leiomyomas, fibromas, neurofibromas and lymphomas. With the exception of lymphomas and neurofibromas, which are seen with greater frequency in the ileum, the other focus preferably in the jejunum [12].

In younger patients the adenocarcinoma topping with $30 \%$ to $50 \%$ of cases, however, in the elderly, the carcinoid tumor has slightly higher incidence. In other cases, higher prevalence of lymphomas, $20 \%$ variable to $65 \%[13]$.

Most symptomatic of neoplastic lesions is evil. Adenocarcinomas are found in the duodenum and proximal jejunum in about 50\% of the opportunities, and are associated with some pre malignant conditions, such as Crohn's disease, familial adenomatous polyposis and Gardner syndrome. When located in the ileum, are demonstrating clinically with pain, nausea and bloating[14]. The suspected diagnosis is usually made through radiological examination contrasted and confirmation by surgical exploration [12]. 


\section{TREatMent}

The general principle of treatment of primary small intestine malignant blastomas is resection with free surgical margins, associated or not to locoregional lymphadenectomy, depending on the histological type and surgical staging of neoplasia [14].

The treatment of choice is the resection of the tumor with safety margins of at least $5 \mathrm{~cm}$, associated with locoregional lymphadenectomy. Polypectomy is recommended when the malignant lesion if has its sights trained on a polyp is smaller than $2 \mathrm{~cm}$. The pancreaticoduodenectomy is indicated in periampulares and compromises the right hemicolectomy when located in the terminal ileum. The poor prognosis of these neoplasms is related to the advanced stage when diagnosed[15].

In cases of metastatic tumors, the conduct is preferably conservative, reserving surgical therapy primarily to the hemorrhagic and obstructive complications[7].

Between $50 \%$ to $80 \%$ have metastasis the distance on the occasion of the first approach. Chemotherapy and radiation therapy, as demonstrated our results, have therapeutic value of little significance [15].

\section{REFERENCES}

[1] Olmstedw w. Tumors of small intestine with or in malignant predisposition. Review of literature. Gastroint. Radiol. 1987; 12 :131-3.

[2] Siegel, Miller RL KD, Jemal a. Cancer statistics, 2015. CA Cancer J Clin 2015; 65:5.

[3] Paski SC, EC Semrad. Small bowel tumors. Gastrointest Endosc Clin N Am. 2009. Jul; 19 (3): 461-79. Jul; 19 (3): 461-79.

[4] Weiss NS, Yang CP. Incidence of histologic types of cancer of the small intestine. J Natl Cancer Inst 1987; 78:653.

[5] Haselkorn T, Whittemore AS, Lilienfeld. Incidence of small bowel cancer in the United States and worldwide: geographic, temporal, and racial differences. Cancer Causes Control 2005; 16:781.

[6] Dorman JE, Floyd And Cohn, IJ. Malignant neoplasms of the small bowel. Am. j. Surg. 1967; 113:131-4.

[7] R Vaidya, Habermann TM, Donohue JH, Ristow KM, Maurer MJ, Macon, WR, Colgan JP, Not DJ, Ansell SM, Porrata LF, Micallef IN, Johnston SC, Markovic SN, Thompson CA, Nowakowski GS, Witzig TE. Bowel perforation in intestinal lymphoma: incidence and clinical features. Ann Oncol. 2013 Sep; 24 (9): 2439-43.

[8] Bell JL, Edwards MJ, Pollock RE. Tumors of the small intestine. In: rabbit, J.C.U. (Ed): clinical and gastrointestinal surgery.2nd Edition. Rio de Janeiro, Medsi, 1996, pp. 58189.

[9] O'Riordan BG, Vilor M, Herrera 1. Small bowel tumors: an overview. Dig Dis. 1996 JulAug; 14 (4): 245-57.

[10] McLaughlin RD, Maher MM. Primary malignant diseases of the small intestine. AJR Am J Roentgenol 2013; 201: W9.

[11] Bilimoria KY, Bentrem DJ, Wayne JD, et al. Small bowel cancer in the United States: changes in epidemiology, treatment, and survival over the last 20 years. Ann Surg 2009; 249:63.

[12] Gabos S, Berkel J, Band P, et al. Small bowel cancer in western Canada. Int J Epidemiol 1993; 22:198.

[13] Islam RS, Leighton JA, Pasha SF. Evaluation and management of small-boweltumors in the era of deep enteroscopy. Gastrointest Endosc. 2014; May; 79 (5): 732-40.

[14] Schwartz GD, Barkin JS. Small bowel tumors. Gastrointest Endosc Clin N Am. 2006 Apr; 16 (2): 267-75.

[15] Johnson AM, Harman LK, Hanks Jb. Primary small bowel malignancies. Ann. Surg. $1985 ; 51: 31-6$. 